\title{
Ensino de ciências naturais e alfabetização científica: Esquete 'a dança do átomo'
}

\author{
Natural science education and scientific literacy: skit 'the atom's dance' \\ Ricardo Eugenio Dill'; Luciana Richter²; André Boccasius Siqueira ${ }^{3}$ \\ 'Licenciado em Ciências Biológicas, Centro de Educação Superior Norte do RS - CESNORS, Universidade Federal de Santa Maria - UFSM, \\ Campus de Palmeira das Missões. Tecnólogo em Agroindústria pela Universidade Estadual do Rio Grande do Sul - UERGS. \\ 'Licenciada em Ciências Biológicas; Mestre em Educação/UFSM. Docente do Curso de Ciências Biológicas, Laboratório de Ensino, Centro \\ de Educação Superior Norte do RS - CESNORS, Universidade Federal de Santa Maria - UFSM, Campus de Palmeira das Missões. \\ ${ }^{3}$ Licenciado em Ciências: Habilitação em Biologia, Mestre em Educação Básica; Doutor em Educação/UNISINOS. Docente do Curso de \\ Ciências Biológicas, Laboratório de Ensino, Centro de Educação Superior Norte do RS - CESNORS, Universidade Federal de Santa Maria - \\ UFSM, Campus de Palmeira das Missões. Grupo de pesquisa AnPAP-EA/CNPq/UNISUL.
}

\begin{abstract}
Resumo
O presente texto relata uma experiência didática da área de Ciências Naturais desenvolvida com estudantes do ensino fundamental por meio do recurso de dramatização. Essa metodologia objetivou promover a compreensão de uma temática científica abstrata como é o caso do ensino dos átomos. A representação da estrutura atômica aos discentes foi dirigida pelo educador e mediada por questionamentos sobre os componentes que formavam o átomo (elétrons, prótons e nêutrons). A ação dos alunos ocorreu a partir das indagações do professor ao decorrer da dramatização e consistiu em quatro atos: a composição do átomo; a ionização; os saltos quânticos de um elétron e a fissão nuclear. Concluiu-se que a dramatização a partir do esquete em sala de aula favoreceu a contextualização do tema de estudo aos alunos e colaborou para de uma forma mais lúdica, planificar os saberes dos estudantes sobre a estrutura atômica.
\end{abstract}

Palavras Chave: Ensino de ciências. Metodologia de Ensino de Ciências. Estrutura atômica. Dramatização.

\begin{abstract}
This text is a report about a didactic experience of Natural Science with the view to promote learning of students of Basic Education using dramatization as a cooperater to the comprehension off an abstract theme about scientific knowledge, as is the atomic structure of chemicals. The representation of the atomic structure by the students was coordinate by the teacher through questions to the groups who represented the different components of the atom (Electrons, Protons and Neutrons). The action from the questions of the teacher consisted in to acts: the atom composition; the ionization; quantum leaps of an electron; and the nuclear fission. It follows that the students had a better comprehension of the theme from the skit in the classroom.
\end{abstract}

Keywords: Science teaching. Science teaching methodology. Atomic structure. Dramatization. 
"Você não é uma entidade isolada, mas uma parte única e insubstituível do cosmo. Não se esqueça disso. Você é uma peça essencial do quebra-cabeça da humanidade". (Epicteto, A arte de viver)

\section{INTRODUÇÃO}

A escola é o meio institucional que envolve a educação do ser humano, não podendo ser concebida como uma fábrica, cujo "produto final" é um objeto. A educação não tolera a simplificação do ser humano, mas considera suas experiências, relações e valores, cada um contribuindo com sua parte para formar o todo da educação e constituir uma territorialidade espacial e cultural, conforme anunciamos na epígrafe deste texto. A escola tem o verdadeiro sentido de conseguir mobilizar todas as dimensões pessoais, simbólicas e políticas da vida escolar, não reduzindo o pensamento e a ação educativa ao incremento do conhecimento científico e desenvolvimento de habilidades técnicas (TOBASE; GESTEIRA; TAKAHASHI, 2007).

Consideramos, por conseguinte, que o ensino de Ciências deve se fundamentar na qualidade e desenvolvimento de uma postura científica e crítica pelos estudantes. Essa perspectiva é primordial, uma vez que o aluno tende a questionar e argumentar para buscar respostas e consequentemente um aprendizado significativo. Sendo assim, torna-se importante o estudo e o desenvolvimento de alternativas metodológicas para a melhoria da qualidade deste ensino (MARANDINO, 2003).

O currículo escolar incentiva os professores a adotarem uma abordagem flexível no ensino de ciências, quando diz que os alunos devem ser ensinados que a ciência propõe a pensar criativamente, para tentar explicar, por exemplo, como os organismos vivos e as coisas não vivas funcionam, interagem e se movimentam. Os alunos aprendem de diferentes maneiras o tempo todo e não existe uma única forma certa para que todos compreendam (FOREMAN, 2010). Nesta direção, no entender de Macedo (2004, p. 129) "o currículo é sempre um espaço/tempo de transição em que sujeitos negociam suas identidades". Na escola não se ensina de fato a Ciência, o que se ensina são "fragmentos de uma ciência que vem em pedacinhos e que, na verdade, não dá possibilidade ao aluno de entender a Ciência" (GARCIA; MOREIRA, 2003, p. 31). É por esse motivo que o profissional docente na educação escolar é uma das pessoas indicadas para fazer as ligações entre os conhecimentos acadêmicos e o que os estudantes vivenciam em suas experiências cotidianas e em seus saberes locais, criando ou adensando o saber escolar.

Um modo de ensinar ciências é através da pesquisa, processo no qual os estudantes são incentivados a conhecer, em diversificadas fontes, o tema de estudo. É pertinente verificar o que Calil (2009, p. 140) assevera sobre a pesquisa escolar. Nas palavras da autora "a pesquisa é um precioso instrumento que, se utilizado de forma consciente pelo docente, aumentará o nível de formação dos alunos, desenvolvendo o seu senso crítico e a sua capacidade de associar o aprendizado escolar com o cotidiano".

Neste sentido, a utilização de diferentes abordagens metodológicas para os conteúdos curriculares permite atender a heterogeneidade de estilos de aprendizagem dos alunos, dando significados àquilo que eles já conhecem em relação ao que conhecerão e experimentarão na escola. Em outros termos, o educando ressignifica seus saberes a partir de sua vivência. Assim, abordagens ativas e afetivas de aprendizagem, como a dramatização, envolvem o intelecto de maneira prazerosa e menos ameaçadora, devendo ter um papel muito maior no ensino de ciências do que tiveram no passado (FOREMAN, 2010).

Nesse contexto, o que moveu a realização da atividade que ora relatamos, foi a necessidade de vivenciar o conteúdo estudado nas aulas de ciências a fim de melhor compreender o estudo dos átomos por parte dos educandos. Em outros termos, realizar uma dramatização, envolvendo os estudantes a partir de estímulos cognitivos por parte do professor, pode ser um ato eficaz para dinamizar as aulas de Ciências da Natureza e compreender através do esquete, um possível movimento das partículas constituintes do átomo.

É nesse aspecto que, segundo Foreman (2010), a dramatização, como forma de modelagem física, atua como um instrumento que permite auxiliar os alunos a enxergar e a entender conceitos científicos abstratos, podendo representar ou exemplificar coisas que não podem ser colocadas facilmente em palavras. Do ponto de vista didático, Haidt (2004) evidencia que a representação de papéis, ou se sentir constituído no objeto representativo, apresenta objetivos como: proporcionar uma situação de aprendizagem clara e específica que facilite a percepção e análise de situações reais de vida, ajudando o aluno a compreender melhor os fatos e fenômenos estudados; facilitar a comunicação de situações problemáticas e sua 
posterior análise, evidenciando os pontos críticos e contribuindo para a iniciação de possíveis alternativas de solução; e desenvolver o senso de observação e a capacidade de expressar-se pela representação corporal e dramática. Esse método é relevante ao ensino de Ciências, porque, como Oliveira et al. (2005, p. 01) destacam, "a linguagem teatral como principal instrumento, por ser extremamente dialógica, por estabelecer relação com a inventividade da ciência e permitir uma ação espontânea dos participantes.". Integra, desse modo, o educando ao tema que se está estudando em sala de aula.

Consideramos, todavia, que o diálogo tem também papel essencial à aprendizagem dos estudantes, pois possibilita trocas de conhecimentos entre os diversos sujeitos da aprendizagem. A verbalização, muitas vezes, leva à compreensão, pois, "entender leva a agir" (FINE, 1997 apud AU, 2011, p. 258). O aprender pela forma do diálogo significa, na compreensão de $\mathrm{Au}$ (2011, p. 252), "nomear o mundo juntamente com os outros, em um ato social, processo que, por sua vez, o ajuda a entendê-lo por conta própria". É perante essas colocações que nossas ideias podem ser verbalizadas ou expressas de outro modo, no entanto, jamais as poderemos colocar na mente de uma pessoa sem que ela queira e sem o interesse do interlocutor com o qual dialogamos. Aprendemos sobre o que nos diz alguma coisa, que nos tem significado, seja teórico ou prático, ou ambos ao mesmo tempo. Assim, a aprendizagem através de esquete, no entender de Spagnol et al. (2013, p. 186) é "uma técnica teatral caracterizada, sobretudo, por uma apresentação ligeira capaz de promover entendimento e suscitar humor, a partir da sátira, às vezes literária, às vezes grotesca, da vida contemporânea ou de uma realidade". No presente relato, apresentamos "a dança do átomo" que é também conhecida como a ideia dos cientistas do modo como os átomos agem em sua configuração química quando se apresentam isolados ou em ligações com outros elementos atômicos, isto é, nas denominadas ligações químicas.

O uso da dramatização no processo didático contribui dessa maneira para aumentar o nível de participação dos alunos estimulando o interesse, pois se supõe que atividades diferenciadas despertam um envolvimento maior e intensificam a participação dos discentes no ato de aprender (HAIDT, 2004), uma vez que aprender ciências exige entre outras necessidades e habilidades, motivação e diálogo.

Uma das características das atividades lúdi- cas é a voluntariedade. A participação dos alunos deve ser, portanto, uma decisão voluntária que prescinde de qualquer outra recompensa além do próprio envolvimento. Quando não há a decisão voluntária de participar qualquer atividade perde seu caráter lúdico, pois ninguém considera prazerosa uma atividade realizada à custa de algum tipo de coerção (TRIVELATO; SILVA, 2011) A escola é o lugar onde damos os primeiros passos com ludicidade, ou seja, as séries iniciais necessitam de metodologias que abordem de forma lúdica a transposição dos conhecimentos. No entanto, à medida que as crianças vão avançando, essas metodologias didáticas vão sendo menos empregadas e as aulas se tornam cada vez mais tradicionais onde o diálogo é direcionado apenas ao conteúdo escolar. A esse processo denomina-se seriedade e embora exista muita seriedade na dramatização, há também estudo, afeto, comprometimento, prazer, ludicidade, amorosidade e vontade, valores que fazem com que as habilidades cognitivas sejam mais facilmente despertadas.

O desenvolvimento da atividade dramática pode variar segundo o tempo, os recursos materiais, o espaço e o local disponível para a encenação. Por este motivo, para a realização desse recurso em sala de aula é fundamental o planejamento e a definição dos objetivos, conforme o cronograma escolar. A dramatização respeita alguns momentos, inicialmente, os temas a serem abordados são apresentados aos alunos, bem como a explicitação dos objetivos, para que os estudantes compreendam a finalidade do estudo, facilitando a contextualização do conteúdo a ser apresentado. Em seguida, é realizado o aquecimento, onde o aluno busca as informações necessárias para a elaboração da dramatização (TOBASE; GESTEIRA; TAKAHASHI, 2007). O aquecimento consiste no momento em que a "atriz" ou o "ator" reúne todo o material e as técnicas a serem seguidas e escolhe o melhor para tal apresentação/representação.

De maneira geral, este relato de experiência pedagógica, desenvolvido em uma aula de Ciências com os alunos da oitava série de uma escola da rede pública de ensino no município de Palmeira das Missões, objetivou esclarecer, aprofundar e didaticamente favorecer a assimilação dos conhecimentos sobre a estrutura atômica, seus componentes e distribuição e o processo de fissão nuclear. A seguir, apresentamos nossa metodologia adotada. 


\section{MÉTODO}

A dramatização foi planejada e roteirizada pelo professor em formação como atividade de contextualização dos conteúdos curriculares de Química da disciplina de Ciências. Os discentes aos quais se propôs a atividade eram pertencentes à oitava série do Ensino Fundamental de uma escola estadual de ensino básico no norte do estado do Rio Grande do Sul. Para dar início à dramatização, a classe foi segmentada em três grupos para encenar as partículas formadoras da estrutura atômica e um grupo atuou como as energias envolvidas na distribuição eletrônica dos elementos.

O primeiro grupo foi composto por cinco estudantes representando os prótons e usavam trajes de cor verde. O segundo grupo também formado por cinco educandos representaram os nêutrons e estavam usando vestes de cor branca. Esses dois grupos iniciaram a atuação no centro de um círculo intercalando cada integrante, assim juntos representando o núcleo. O terceiro grupo foi formado por mais cinco alunos que simularam os elétrons e estavam vestidos de vermelho, ficando dispostos em círculos ao redor do núcleo, na eletrosfera, de forma a respeitar a distribuição dos elétrons em cada nível de energia. Por sua vez, o último grupo composto por dois estudantes simularam as energias envolvidas quando um elétron "passa" de um nível de energia para o outro, onde um dos alunos representava o Quantum e o outro o Fóton. A ordem cronológica da atividade lúdica de dramatização seguiu, portanto, os seguintes atos:

Primeiro ato: A composição do átomo. A dramatização foi iniciada com os personagens tomando as suas posições. Houve inicialmente a dança em pares das partículas de próton e nêutron formando o núcleo, na sequência entraram os elétrons girando ao redor do núcleo.

Segundo ato: $A$ ionização. $\mathrm{O}$ ato caracterizou-se pela demonstração da produção de um íon, ou seja, uma espécie química eletricamente carregada, onde os estudantes encenaram a perda um elétron resultando num íon cátion.

Terceiro ato: Os saltos quânticos de um elétron. O átomo voltou ao seu estado natural neutro, e se deu início à representação para demostrar o que ocorre com o elétron quando ele recebe um quantum e libera um fóton. Nessa etapa entraram na dramatização os demais participantes.

Quarto ato: A fissão nuclear. Nesse ato os educandos representaram o que ocorre quando uma partícula eletricamente neutra se colide com o núcleo do átomo. Esse passo buscava responder qual seria o resultado dessa colisão.

A dramatização inicialmente foi intermediada pelo professor através de indagações referentes ao conteúdo. As respostas dos questionamentos deveriam ser respondidas por meio da atuação dos constituintes do átomo envolvidos em cada ato. Posteriormente, os alunos, de forma autônoma, reencenaram os quatro atos explicando para os demais integrantes do grupo, quem estavam representando bem como as funções na estrutura atômica. A última atuação nesse processo dramático contou com a realização da sequência dos atos ao som de uma música, de forma a preconizar o átomo a "dançar" e se mover numa representação do movimento atômico natural.

\section{RESULTADOS E DISCUSSÃO}

A atividade de dramatização transcorreu com a participação de todos os alunos sob a mediação do professor, ou seja, o docente era o "diretor" do esquete. Considerando que no entendimento de Haidt (2004), a dramatização consiste na representação de um fato ou fenômeno de forma espontânea ou planejada, a atividade foi previamente estudada e ensaiada com o intuito de haver a apreensão dos estudantes acerca do tema. Para isso, foram feitos questionamentos antes do início da dramatização tais como "porque eles representavam tal componente atômico", "quais eram esses componentes"; "em que locais eles podiam ser encontrados na estrutura do átomo"; "porque os elétrons estão configurados da maneira que os livros ilustram" e "o que fazia o núcleo ser da forma que eles representaram".

Para responder essas indagações, os alunos iniciaram a dramatização formando o átomo a partir dos personagens que eles representavam (elétrons, prótons, nêutrons). Os estudantes perceberam que cada um representava um constituinte do átomo, no entanto, isolados não conseguiam representar o átomo em sua totalidade, necessitando, portanto, que estivessem juntos para tornar possível essa representação. Na sequência da 
ionização do átomo, foi demonstrando a perda de um elétron para o meio comprovando o que ocorreria na configuração eletrônica. Os colegas puderam mostrar pelo esquete que o átomo em seu estado natural, havia se tornado um íon cátion. Como a entidade atômica estava instável, os educandos concluíram que, para voltar a seu estado fundamental, um elétron deveria voltar a estar presente no último nível de energia. Dessa maneira o aluno representante dessa partícula retornou ao grupo na atuação. Com o átomo no seu estado fundamental, os alunos puderam perceber como os elétrons estariam distribuídos na eletrosfera segundo as teorias químicas e como eles realizam os saltos quânticos nos níveis de energia. Representaram ainda a fissão do átomo, e nesse momento um dos alunos representantes das energias entrou em cena como um nêutron fazendo com que os alunos que estavam representando o núcleo se dividissem em dois grupos distintos, dando origem a dois diferentes átomos de elementos químicos.

Através da ação coletiva supramencionada, esperávamos que o ditado autoperpetuante "ouço e esqueço, vejo e lembro, faço entendo" mostrasse a importância das atividades práticas e, uma dessas técnicas experimentais, criativas e práticas que poderiam ser utilizadas para preconizar isso, seria a dramatização (VAN MENTS, 1983, p. 14-23). Esse recurso pedagógico é, portanto, uma técnica ativa e socializadora, de grande valor formativo, pois integra as dimensões cognitivas e afetivas do processo educacional e instrumental. Como prática educativa, entretanto, ela deve ser considerada dentro de uma sequência definida de estudo que assim consistirá como um recurso a mais para ser utilizado no processo de ensino aprendizagem com a intenção de atingir certos objetivos educacionais (HAIDT, 2004).

A imaginação, ao invés de conhecimento dos fatos, é o fator mais importante e necessário para aprender ciência. Sem dúvida, a ciência é parte integral da cultura moderna e deve buscar ampliar a imaginação para refletir em seu ensino. É pertinente que os alunos tenham a oportunidade de responder a certos aspectos da ciência de maneira imaginativa e criativa (FOREMAN, 2010). Acerca desse sentimento há pesquisas sobre o cérebro que ajudam a construir a aprendizagem. Elas sugerem que o movimento pode ser uma estratégia efetiva de ensino para desenvolver redes permanentes de conexão no cérebro (SMITH, 1999), pois é através do movimento, ou seja, são as percepções de mudanças corporais, como acreditava Willian
James (1884 apud JAQUES; VICARI, 2005), que resultam na emoção. Isso significa que a emoção é o resultado de uma reação corporal a um evento, no nosso caso o esquete teatral. De acordo com o mesmo autor, uma emoção possui um padrão único de mudanças fisiológicas, do esqueleto e dos músculos, já que a nossa experiência de emoção é função direta do feedback do corpo. Não podemos esquecer ainda de considerar a motivação como outro fator importante para efetividade do trabalho, pois a emoção positiva por parte dos alunos durante a atividade foi fundamental para eles atuarem na representação atômica. De acordo com as concepções de Ames (1990 apud JAQUES; VICARI 2005), a motivação do estudante tem a ver com o seu desejo de participar no processo de aprendizagem. É perante essas colocações que se deve priorizar que o estudante construa o conhecimento por ele mesmo afinal quando motivados, os alunos buscam encontrar respostas aos seus problemas e satisfazer suas necessidades. Nesta direção, Vygotsky (1962) evidencia que a motivação é a razão da ação. É a motivação que impulsiona os interesses, os desejos e as atitudes particulares dos sujeitos e é nesta perspectiva que os sujeitos aprendentes estavam a buscar um vocabulário específico - a química.

A dramatização exige mais que apenas movimento corporal, envolve também a necessidade de interação e de cooperação e é assim que se pode satisfazer as necessidades de uma variedade de estilos de aprendizagem e de sincronismo. A dramatização sobre nossas percepções é vista como uma experiência de aprendizagem valiosa que movimenta e integra diferentes áreas do cérebro. Ao encontro desse conceito, as atividades criativas como a dramatização não apenas permitem que os alunos se comuniquem usando códigos linguísticos familiares, mas podem estimulá-los a se comunicar usando uma linguagem restrita aos cientistas desenvolvendo assim o uso do vocabulário científico (SMITH, 1999; FOREMAN, 2010). Esse processo de apreensão e aplicação correta dos termos científicos é o que alguns autores denominam de Alfabetização Científica (CHASSOT, 2003).

Por conseguinte, a proposta de mudança curricular no Brasil defende a necessidade de se praticar mais a experimentação nas aulas de Ciências, mas infelizmente por muitas décadas ainda prevalece uma orientação mais livresca do que experimental. Defendemos que a escola deve ser um espaço informativo e formativo e a educação, uma prática de formação da pessoa. Por este 
motivo, é necessário que o espaço escolar não se limite somente ao repasse de informações sobre um determinado assunto, mas é imprescindível, também, que a escola enquanto formadora de cidadãos tenha por missão contribuir para que o aluno desenvolva habilidades e competências que lhe permitam trabalhar as informações (GARCIA, 2005) de modo lúdico.

\section{CONSIDERAÇÕES FINAIS}

É importante que o ensino de Ciências permita ao aluno associar e relacionar os conteúdos escolares com aplicações em sua vida e é nesse processo que o professor transforma-se em um guia, mediador ou direcionador da aprendizagem propondo diretamente a vinculação dos conteúdos curriculares com a vivência do cotidiano e promovendo, desse modo, uma aprendizagem significativa para seus alunos.

A utilização da dramatização para explicar temas complexos na disciplina de ciências é um instrumento facilitador na relação de ensino e aprendizagem, pois permite que os alunos formulem suas próprias concepções através da representação de conceitos abstratos e científicos.

Acredita-se que atividades interativas na educação básica promovem o entusiasmo de estudantes e, por extensão, também da comunidade escolar acerca de temas relacionados à área de Ciências Naturais, pois são utilizadas diversificadas linguagens, tanto acadêmicas quanto cotidianas, como, por exemplo, os movimentos corporais promovidos pela dança. É assim que se torna possível obter a alfabetização científica de crianças, jovens, adultos, anciãos e de estudantes tanto da educação básica quanto do ensino superior.

Defende-se que o ensino de Ciências seja realizado com amorosidade, afeto, lucidez e dedicação a fim de que se alcance o âmago dos discentes e se desperte neles, cada vez mais, o prazer em estudar, em participar das atividades e principalmente, o prazer em ser cidadão no seu espaço de tempo educacional.

Buscamos, por fim, conectar nossas considerações com as ideias supra expostas da epígrafe e inter-relacionar nossas concepções sobre o esquete "Dança do Átomo" ao compará-lo com os pensamentos do autor do excerto "A arte de viver". Essa dança ou atividade dramatizada valoriza e destaca as características individuais de cada partícula constituinte do átomo (prótons, nêutrons e elétrons). A execução de várias ações de maneira vigorosa e acelerada tanto de modo individual como coletivo permitiram as conexões entre uma parte e a outra, daí a necessidade de cada estudante estar presente com seus movimentos e suas energias, afinal, nesse processo, cada um é insubstituível em suas funções e qualidades. Cada discente foi, portanto, essencial para o desenvolvimento da dramatização, e foram preponderantes em suas funções de essencialidade para a constituição do todo. É assim, também, que objetivamos que seja o ensino de Ciências na educação básica - lúdico e motivador - conforme tentamos valorizar e representar na presente reflexão.

\section{AGRADECIMENTOS}

Agradecemos pela leitura atenta, correções precisas e revisão minuciosa da colega e amiga Regiane Zanovello, que não mediu esforços em suas valiosas sugestões. Nosso muito obrigado.

\section{REFERÊNCIAS BIBLIOGRÁFICAS}

AU, W. Lutando com o texto: contextualizar e recontextualizar a pedagogia crítica de Freire. APPLE, M. W.; AU, W.; ANDIN, L. A. (orgs.). Educação Crítica: Análise Internacional. Porto Alegre: Artmed, 2011. (p. 250-261).

CALIL, P. O Professor-Pesquisador no Ensino de Ciências. Curitiba: Editora IBPEX, 2009. (Série: Metodologia do Ensino de Biologia e Química, 2).

CHASSOT, A. Alfabetização científica: uma possibilidade para a inclusão social. Revista Brasileira de Educação. n. 22. jan./fev./mar./abr. 2003. p. 89-100.

FOREMAN, J. O uso da dramatização para promover e desenvolver a compreensão dos alunos sobre conceitos científicos. In: WARD, H.; RODEN, J.; HEWLETT, C.; FOREMAN, J. Ensino de Ciências. Porto Alegre: Artmed. 2010. (p. 139-160).

GARCIA, L. A. M. G. Competências e Habilidades: você sabe lidar com isso?. Educação e Ciência On-Line, Brasília: Universidade de Brasília. 2005. Disponível em: <http://uvnt.universidadevirtual.br/ ciencias/002.htm> Acesso em: 11 mar. 2013.

GARCIA; R. L.; MOREIRA, A. F. B. Começando uma conversa sobre currículo. In: GARCIA; R. L.; MOREIRA, A. F. B. (orgs.). Currículo na con- 
temporaneidade: incertezas e desafios. São Paulo: Cortez, 2003. (p. 7-39).

HAIDT, R. C. C. Procedimentos de ensino-aprendizagem socializantes: Dramatização. In: HAIDT, R. C. C. Curso de didática geral. $7^{a}$ ed. São Paulo: Ática. 2004. p. 179-182. (Série Educação).

JAQUES, P. A. ; VICARI, R. M. Estado da Arte em Ambientes Inteligentes de Aprendizagem que Consideram a Afetividade do Aluno. Informática na educação, UFRGS: Porto Alegre, v. 8, n. 1, p. 15-38, 2005. Disponível em: <http://www.pgie.ufrgs.br/ revista>. Acesso em 11 maio 2013.

MACEDO, E. Ciência, tecnologia e desenvolvimento: uma visão cultural do currículo de Ciências. In: LOPES, A. C.; MACEDO, E. (orgs.). Currículo de Ciências em debate. Campinas: Papirus, 2004. (p. 119-154).

MARANDINO, M. A prática de ensino nas licenciaturas e a pesquisa em ensino de ciências: questões atuais. Cadernos Brasileiros Ensino de Física, v.20, n.2: p.168-193, ago. 2003. Disponível em: <http:// www.diaadiaeducacao.pr.gov.br/diaadia/diadia/ arquivos/File/conteudo/artigos_teses/Biologia/ Artigos/pratica_de_ensino.pdf > . Acesso em: 06 mar. 2013.

OLIVEIRA, D. F. de; MENDONÇA, C. C. R.; MEIRELLES, R. M. S.; JORGE, T. C. A.; LUZ, M. R. M. Oficinas teatrais: estratégias inovadoras para diagnóstico de concepções e problemas na educação sobre temas de saúde. V ENCONTRO NACIONAL DE PESQUISA EM EDUCAÇÃO EM CIÊNCIAS. Anais... 2005. Disponível em: <http://www.nutes. ufrj.br/abrapec/venpec/conteudo/artigos/1/pdf/ p799.pdf>. Acesso em: 04 maio 2013.

SMITH, A. Accelerated Learning in Practice. Stafford: Network Educational Press. 1999.

SPAGNOL, C. A.; MONTEIRO, L. A. S.; PAULA, C. L.; BASTOS, J. M.; HONORATO, J. A. G.

Vivenciando situações de conflito no contexto da Enfermagem: $\mathrm{O}$ esquete como estratégia de ensino-aprendizagem. Esc. Anna Nery (impr.) jan.-mar. 2013; 17 (1), p. 184-189. Disponível em: <http:// www.scielo.br/pdf/ean/v17n1/26.pdf $>$. Acesso em 04 maio 2013.

TOBASE, L.; GESTEIRA, C. R.; TAKAHASHI, T. Revisão de literatura: a utilização da dramatização no ensino de enfermagem. Revista Eletrônica de Enfermagem, v. 09, n. 01, p. 214-228, 2007. Disponível em: <http://www.fen.ufg.br/revista/v9/n1/ v9n1a17.htm>. Acesso em: 10 abr. 2013.

TRIVELATO, S. F.; SILVA, R. L. F. Atividade lúdica e ensino de ciências - a biodiversidade como exemplo. In: TRIVELATO, S. F.; SILVA, R. L. F. Ensino de ciências. São Paulo: Cengage Learning. 2011. (Coleção ideias em ação).

VAN MENTS, M. The effective use of role play: a handbook for teachers and trainers. Edição de revisão. London: Kogan Page, 1983.

VYGOTSKY, L. Thought and Language. Cambridge, MA: MIT Press, 1962. 